\title{
Synthaderm in the management of pre-tibial lacerations: a controlled clinical study
}

\author{
A. MARTIN, ${ }^{1}$ N. G. KIRBY, ${ }^{1}$ M. TABONE VASSALLO ${ }^{2} \&$ \\ E. GLUCKSMAN ${ }^{2}$ \\ ${ }^{1}$ Department of Accident and Emergency, Guy's Hospital, and ${ }^{2}$ Department of Accident \\ and Emergency, King's College Hospital, London, England
}

\section{SUMMARY}

A clinical study of patients with pre-tibial lacerations at King's College Hospital and Guy's Hospital, London, England, compared a non-adhesive dressing with Synthaderm. Treatment was randomly allocated.

At King's College Hospital, deep and superficial lacerations were equally distributed, the median time to healing with Synthaderm was significantly $(P<0.02)$ reduced; and the median rate of healing $(\mathrm{mm} /$ day) was significantly $(P<0.01)$ better.

At Guy's Hospital, larger and wider wounds were unequally distributed, with fewer in the control group; in the Synthaderm group, the median rate of healing was increased.

In both centres, the clinical impression was that Synthaderm reduced nursing dressing time and a better scar resulted. Synthaderm improved the rate of healing in pre-tibial lacerations.

\section{INTRODUCTION}

Wounds below the knee heal slowly (Rozner \& Ashby, 1965); pre-tibial injuries are common, particularly in women over the age of 50 (Tandon \& Sutherland, 1973). The usual triangular flap injury has a poor blood supply and healing is slow, averaging between 40 and 60 days (Crawford \& Gipson, 1977). Skin grafting (Jones \& Sanders, 1983) may reduce time to healing but suturing may even delay healing (Sutton \& Pritty, 1985).

Winter (1971) identified the ideal conditions for optimum wound healing: a warm, moist micro-environment increased the mitotic activity of epithelial cells as they proliferated from the germinal epithelium at the edge of the wound, and at hair follicles

Correspondence: Major-General N. G. Kirby, Department of Accident and Emergency, Guy's Hospital, London, England 
or sweat glands. Phagocytes are also most effective at normal body temperature (May $\frac{\mathbb{D}}{0}$ 1982; Lock, 1979). Semi-occlusive dressings improve healing rates of leg ulcers and 3 similar wounds (Bayliss, 1979).

'Synthaderm' is a semi-occlusive dressing with a lower layer of open 'cells' which $\vec{\Rightarrow}$ absorbs excess wound exudate and an impermeable layer of cells at the upper surface $\frac{?}{\circ}$ which reduces evaporation. The dressing permits normal gaseous exchange of the흠 tissues beneath it. The micro-environment approaches the ideal described by Winter. $\frac{\bar{p}}{\vec{D}}$

\section{PATIENTS AND METHOD}

A two-hospital study compares Synthaderm with the hospitals' standard treatment of $\frac{\mathbb{D}}{3}$ pre-tibial wounds in terms of:

(1) rate of healing; and

(2) number of visits for dressings.

The following were recorded with either treatment: number and duration of dressing윽 changes, convenience of use, exudate, infection and evidence of healing.

A total of 156 patients were admitted, 66 at Guy's Hospital (GH) and 90 at King's $\mathbb{D}$ College Hospital $(\mathrm{KCH})$. All patients studied had a laceration on the antero-medial ${ }_{\mathbb{C}}^{+}$ aspect of the leg between the knee and ankle. Important pre-existing medical conditions $\frac{3}{3}$ were noted.

Patients were randomly allocated to Synthaderm or control treatment, the random $\overrightarrow{0}-\overrightarrow{0}$ zation being run in balanced blocks of 10 patients.

Treatment was standardized:

(1) Control: the wound was cleansed with normal saline and a non-adherent dressing applied with a supporting bandage.

(2) Synthaderm: the wound was cleansed with normal saline, Synthaderm applied with a minimum overlap of $2 \mathrm{~cm}$ around the wound, and covered with a supportingo $\overrightarrow{\vec{B}}$ bandage.

In both treatments, the wound was excised and a suture or steristrip applied when: essential. The wound was not exposed longer than necessary. Only chlorhexidine $\frac{\mathbb{\Phi}}{3}$ cream, povidone iodine or silver sulphadiazine were used as topical antiseptics.

Dressing changes were carried out depending on the condition of the wound, particularly the amount of exudate. The first change was normally within $48 \mathrm{~h}, \hat{\Omega}$ subsequent visits were 2-3 times during week 1 and, thereafter, at weekly intervals.

On presentation, either an outline of the wound was traced on sterile transparent 5 acetate film to record size, shape, width and total area of the laceration, or a photograph was taken with a centimetre scale.

A laceration was 'healed' when epithelialization was complete. Time to healing and rate of healing were calculated for each patient. Treatment success was defined as $\tilde{O}$ complete healing. Patients were withdrawn from the study if they did not reattend, $\omega$ developed cellulitis requiring systemic antibiotics, complained of unacceptable pain or interfered with their dressing.

In the statistical analysis, the two-sample t-test was used to compare the twow 
treatment group means or the group mean transformed values when the data were skewed. Non-parametric tests were employed when the data were discrete and these tests are quoted in the results section.

\section{RESULTS}

There were fundamental differences between patient populations, conventional treatment and wound size at the two centres. The results are, therefore, analyzed and reported separately.

\section{King's College Hospital}

Of the 90 patients originally entered, 63 completed the study, 29 conventional treatment and 34 Synthaderm. Two patients on Synthaderm had a local reaction but this was not related to hypersensitivity to Synthaderm. Eight patients, four on each treatment, were lost to follow up. Two patients, one on each treatment, failed to show evidence of healing. Clinical efficacy was, therefore, assessed on 29 patients treated with Synthaderm and 24 treated conventionally.

Most patients presented within $24 \mathrm{~h}$ of injury. Clinical features are shown in Table 1.

Wound characteristics at the time of admission had a skewed dsitribution with respect to width, total area and shape (Figs 1-3). No statistically significant differences between treatment groups for these three variables were noted.

Table 1 Clinical features in patients treated with either Synthaderm $(S)$ or Conventional Dressing (CD) at $\mathrm{KCH}$ or $\mathrm{GH}$

\begin{tabular}{|c|c|c|c|c|}
\hline \multirow[b]{2}{*}{ Variables } & \multicolumn{2}{|c|}{$\mathrm{KCH}$} & \multicolumn{2}{|c|}{ GH } \\
\hline & $S$ & $\mathrm{CD}$ & $\mathbf{S}$ & $\mathrm{CD}$ \\
\hline No. of patients & 34 & 29 & 30 & 28 \\
\hline Males:Females & $7: 27$ & $3: 26$ & $11: 19$ & $14: 14$ \\
\hline Mean age (years) & $58 \cdot 1$ & $68 \cdot 3$ & $56 \cdot 7$ & $57 \cdot 2$ \\
\hline Age range (years) & $11-84$ & $11-92$ & $13-91$ & $14-88$ \\
\hline \multicolumn{5}{|l|}{ In each treatment group } \\
\hline No. of deep wounds & $8(24 \%)$ & $9(31 \%)$ & $17(57 \%)^{*}$ & $9(32 \%)$ \\
\hline $\begin{array}{l}\text { No. of patients } \\
\text { presenting }>24 \mathrm{~h}\end{array}$ & & & & \\
\hline after injury & $5(15 \%)$ & $9(31 \%)$ & $4(13 \%)$ & $9(32 \%)$ \\
\hline No. of subjects & & & & \\
\hline$>61$ years & $20(59 \%)$ & $23(79 \%)$ & $17(57 \%)$ & $16(57 \%)$ \\
\hline $\begin{array}{l}\text { No. of subjects with } \\
\text { lesion } \geqslant 20 \mathrm{~mm} \text { width }\end{array}$ & $8(24 \%)$ & $2(6 \%)$ & $11(37 \%)$ & $0(0 \%)$ \\
\hline $\begin{array}{l}\text { No. of subjects with infected } \\
\text { lesions at presentation }\end{array}$ & $0(0 \%)$ & $2(7 \%)$ & $2(7 \%)$ & $4(14 \%)$ \\
\hline
\end{tabular}

*Significantly different from $\mathrm{CD}$ by $\gamma$-squared test $(P=0.08)$. 


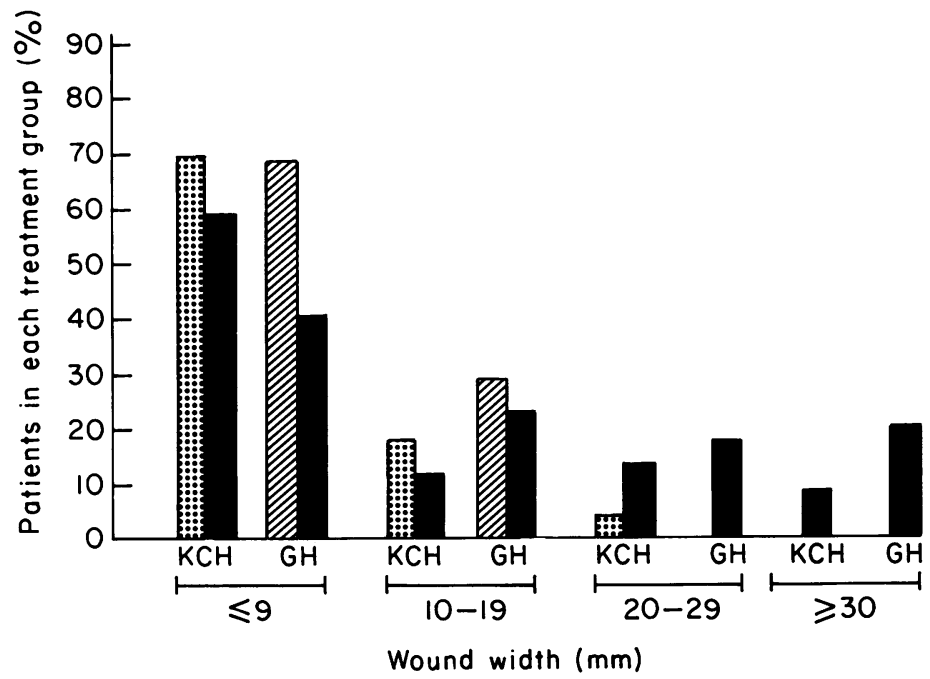

Fig. 1 Distribution of wound width at $\mathrm{KCH}$ and $\mathrm{GH}$.

Conventional treatment at $\mathrm{KCH}$;

WIIA Conventional treatment at $\mathrm{GH}$;

Synthaderm treatment at $\mathrm{KCH}$ and $\mathrm{GH}$.

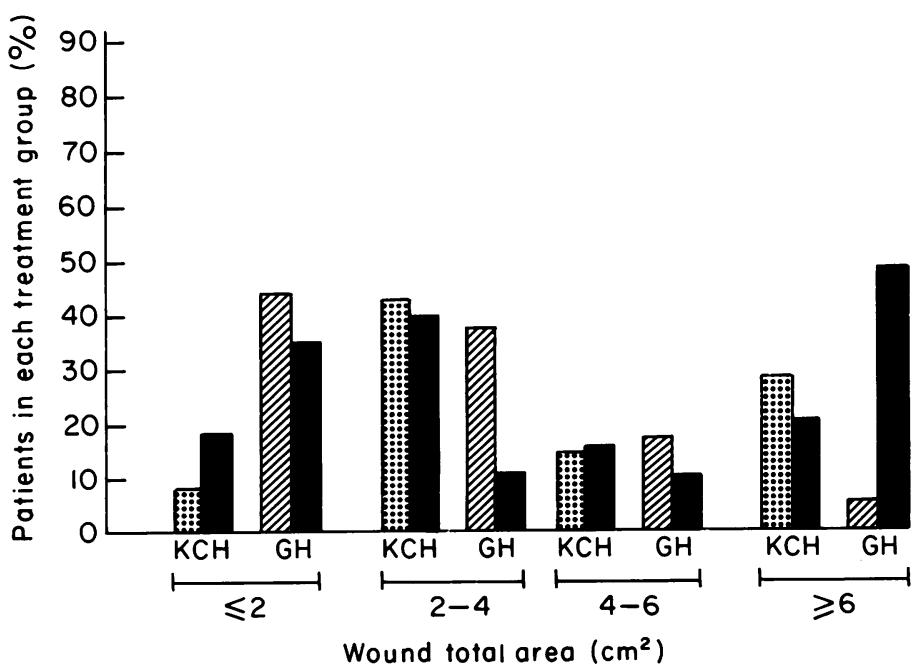

Fig. 2 Distribution of wound total area at $\mathrm{KCH}$ and $\mathrm{GH}$.

The majority of wounds were of the flap type, the remainder being classed as linear of skin loss. More linear and skin loss wounds were allocated by chance to the Synthadern group (Fig. 3). There was an even distribution between the two treatment groups with 


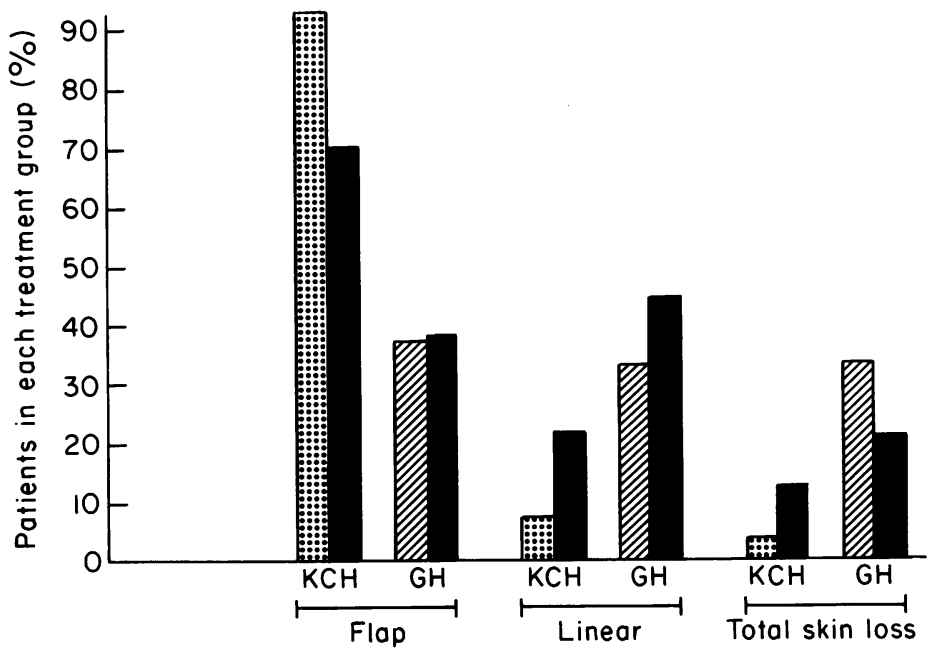

Fig. 3 Distribution of type of wound at $\mathrm{KCH}$ and $\mathrm{GH}$.

respect to depth, oedema, inflammation or infection, and significant exudation. More infections in the conventional group were noted but this did not reach statistical significance.

Two patients had an absent pedal pulse in the conventional group compared to one in the Synthaderm group. Twelve patients with varicose veins were evenly distributed between the treatment groups.

Clinical outcomes are summarized in Table 2.

Table 2 Clinical outcome in patients treated with either Synthaderm (S) or Conventional Dressing (CD) at $\mathrm{KCH}$ or $\mathrm{GH}$

\begin{tabular}{|c|c|c|c|c|}
\hline \multirow[b]{2}{*}{ Variables } & \multicolumn{2}{|c|}{$\mathrm{KCH}$} & \multicolumn{2}{|c|}{ GH } \\
\hline & $\mathbf{S}$ & $\mathrm{CD}$ & $\mathbf{s}$ & $\mathrm{CD}$ \\
\hline Patients lost to follow-up & 4 & 4 & 1 & 2 \\
\hline Withdrawn & 7 & 10 & 2 & 3 \\
\hline No. of patients healed & 34 & 29 & 30 & 28 \\
\hline $\begin{array}{l}\text { Development of infection during } \\
\text { treatment }\end{array}$ & 5 & 7 & 6 & 9 \\
\hline Median number of visits & 6.00 & $7 \cdot 00$ & $9 \cdot 50$ & 8.00 \\
\hline Median time to healed (days) & $23 \cdot 50^{*}$ & 33.00 & $51 \cdot 50$ & $43 \cdot 50$ \\
\hline $\begin{array}{l}\text { Median rate of healing relative to } \\
\text { width of lesion ( } \mathrm{mm} / \text { day) }\end{array}$ & $0 \cdot 23 \S$ & $0 \cdot 16$ & $0 \cdot 27 \ddagger$ & $0 \cdot 14$ \\
\hline $\begin{array}{l}\text { Median rate of healing relative to } \\
\text { total area of lesion }\left(\mathrm{cm}^{2} / \text { day }\right)\end{array}$ & $0 \cdot 16$ & 0.13 & $0 \cdot 11 \dagger$ & 0.04 \\
\hline
\end{tabular}

*Significantly different from $C D$ at Centre $1(P=0.018)$.

$\dagger$ Significantly different from $C D$ at Centre $2(P=0.004)$.

$\ddagger$ Significantly different from CD at Centre $2(P=0.002)$.

$\S$ Significantly different from $C D$ at Centre $1(P=0.01)$. 


\section{Healing time}

(1) At 6 weeks, $59 \%$ of patients in the conventionally treated group were healed compared to $88 \%$ in the Synthaderm group. These data were not normally? distributed but became so on logarithmic transformation. Using the $t$-test on the log values, the time to heal was statistically $(P=0.018)$ significantly shorter in the Synthaderm group.

(2) Rates of healing relative to width ( $\mathrm{mm} / \mathrm{day})$ and total wound area $\left(\mathrm{cm}^{2} / \mathrm{day}\right)$ : the median rate of healing was statistically better for the Synthaderm treated group for width $(P=0.01)$ but not for area $(P>0 \cdot 1)$.

(3) The distribution of number of visits was markedly skewed especially for the $\overrightarrow{0}$ Synthaderm group and non-parametric tests were used to test for comparability $\overrightarrow{\vec{\omega}}$ Although there was a reduction in the number of visits in favour of Synthaderm this did not reach statistical significance $(P=0 \cdot 1$, Kruskal-Wallis).

\section{Guy's Hospital}

Of the 66 patients admitted to the trial, 58 completed the study, 28 conventionaB treatment and 30 Synthaderm. Patients at GH were younger than those at $\mathrm{KCH}$ and almost equally matched male:female (Table 1 ).

Wound width and total area had a skewed distribution (Figs $1 \& 2$ ). The treatmen groups were, therefore, unbalanced, with more larger and deeper wounds being treateog with Synthaderm. This difference between treatment groups was highly significant $(P<0.001)$. More linear and skin loss lesions were seen at this centre but wệ요 uniformly allocated between treatment groups (Fig. 3). A larger proportion of patients with infected wounds received conventional treatment (see Table 1). An unexpected feature was that more patients treated with conventional treatment showed wound응 exudation, which is normally more prevalent under semi-occlusive dressings of the Synthaderm type. Four patients in the Synthaderm group, compared with one patien $\mathbb{R}$ in the conventional group, had no pedal pulse and fifteen patients (evenly distributed had varicose veins.

Healing times and rates of healing relative to width and area are shown in Table 2 亭

(1) At 6 weeks, similar numbers of patients were healed in the two groups, namely $7 / 2 \%$ $(26 \%)$ on conventional treatment and $5 / 28(18 \%)$ on Synthaderm. When healing. time data are plotted on a scatter diagram (Fig. 4), it can be seen that the large lesions healed in the same time as the much smaller lesions. Convex hulls (Efron 1965) which enclose each treatment group at the outermost data points, have been? added to help visualize the scatter.

(2) Median rates of healing were statistically in favour of Synthaderm, both with respect to width $(P=0.002)$ and total area $(P=0.004)$ (Table 2$)$.

(3) A reduction in the median number of visits was not statistically significant aftep logarithmic transformation. 


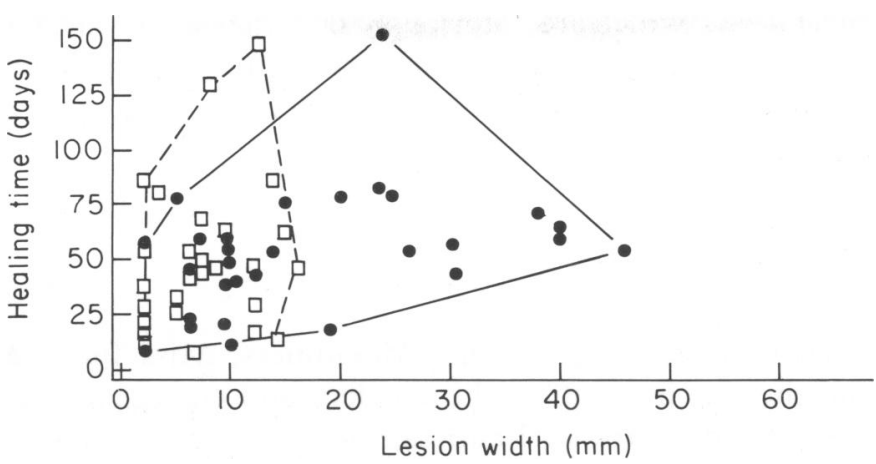

Fig. 4 A scatter diagram of the healing time in days against wound width in millimetres. Convex hulls (Efron, 1965) have been constructed around the outermost points of each treatment group.

Conventional treatment; Synthaderm treatment.

\section{DISCUSSION}

Comparison of different dressings and dressing techniques by controlled clinical trial is notoriously difficult. Variations of site and condition of the wound, blood supply, physiological and clinical state between patients often preclude statistically valid comparisons. Local anatomical factors also magnify the effects of minor trauma and such effects were seen in this trial. However, the choice of a limited site of injury and fairly standard lesion, together with sufficient numbers of patients, enabled valid comparison to be made.

Healing times and healing rates were compared for the conventional and Synthaderm dressing procedures separately at both hospitals (Table 2). At $\mathrm{KCH}$ the healing time was significantly shorter for the Synthaderm-treated group and the healing rate relative to width was also better in the Synthaderm-treated group.

At GH, the rate of healing relative to both width and area was better with Synthaderm, but no statistically significant difference could be shown for the healing time in days. At this hospital, however, the treatment groups were unbalanced and a greater number of the large and deep lacerations were treated with Synthaderm (Martin \& Kirby, 1985).

Although there are differences between the two hospitals, an overall assessment of the results confirms a complementary pattern that the use of a semi-occlusive dressing, Synthaderm, improved the rate of healing and, at one hospital, the total healing time compared to that with non-adherent dressing.

Synthaderm proved to be safe, convenient to use and easy to apply. Clinically, the patient was comfortable and there was less infection in the Synthaderm patients but this did not reach statistical significance.

The time for dressing changes with Synthaderm appeared less than that with controls, this was most likely because of its non adherence. Dressing changes were less painful and more acceptable to the patients. Fewer visits for Synthaderm patients saved medical and nursing time, and reduced ambulance transport. 
In pre-tibial lacerations, which are notoriously slow to heal, the authors conclude thif Synthaderm, by improving the micro-environment, provides a better alternative conventional dressings and improves the healing rate.

\section{ACKNOWLEDGEMENTS}

We thank Dr Tanya Malpass, Miss Anne McGuiness, Miss Fiona MacMillan, Dö Stephen Nash, all the nursing staff in the accident and emergency departments why took part in this study, and Armour Pharmaceutical Company for supplying Syntha derm and statistical advice.

\section{REFERENCES}

Bayliss D. J. (1979) A clinical application for synthaderm, a new plastic dressing material-a new treatment for an old problem. In Symposium on 'Wound Healing, Plastic Surgical and Dermatological Aspectsco Lindgren A. \& Sundell A. B. (eds), pp. 189-203. Holndal, Sweden.

Crawford B. S. \& Gipson M. (1977) The conservative management of pretibial lacerations in elderly patient British fournal of Plastic Surgery 30, 174-6.

Efron B. (1965) The convex hull of a random set of points. Biometrics 52, 131-343.

Jones B. M. \& Sanders R. (1983) Pretibial injuries: a common pitfall. British Medical fournal 286, 502 $\overrightarrow{0}$

Lock P.M. (1979) The effects of temperature on mitotic activity at the edge of experimental wound Symposium on 'Wound Healing, Plastic Surgical and Dermatological Aspects', Lindgren A. \& Sundell (eds), pp. 103-8. Holndal, Sweden.

Martin T. \& Kirby N.G. (1985) Clinical aspects of Synthaderm. In Advances in Wound Management Symposium, University of Wales Institute of Science and Technology, Cardiff, Wales, Turner T. D., Schmi R. S. \& Harding H. G. (eds), pp. 31-8. Chichester, Wiley.

May S. R. (1982) Physiological activity from an occlusive wound dressing. In Symposium on 'Wound Healing Birmingham, England, Lawrence J. C. (ed.), p. 35. The Medical Publishing Foundation.

Rozner L. \& Ashby E. C. (1965) Anatomical and physiological factors in below-knee wounds. Lancet i, 1362 5.

Sutton R. \& Pritty P. (1985) Use of sutures or adhesive tapes for primary closure of pretibial lacerations. British Medical fournal 290, 1627.

Tandon S. N. \& Sutherland A.B. (1973) Pretibial lacerations. British fournal of Plastic Surgery 26, 172-5:

Winter G.D. (1971) Formation of the healing of skin wounds and the influence of dressing on the repa process. In Surgical Dressings and Wound Healing, Harkiss K. J. (ed.), pp. 46-60. London, Bradfor University Press. 